\title{
Making the case for Case Studies
}

\author{
Julie Solomon
}

Nature Clinical Practice Endocrinology \& Metabolism is a journal designed to lighten the reading load for busy doctors; why, then, does it include Case Studies? Isn't the case study just a bit of light reading? It depends on what it is designed to do. For readers of this journal, it may be helpful to revisit and update the ideas I previously outlined (Solomon J Nat Clin Pract Gastroenterol Hepatol 2005, 2: 117). So, what is the role of the Case Study?

Case Studies should act as instructive examples to people who might encounter similar problems. Ideally, in medicine, Case Studies should detail a particular medical case, describing the background of the patient and any clues the physician picked up (or should have, with hindsight). They should discuss investigations undertaken in order to determine a diagnosis or differentiate between possible diagnoses, and should indicate the course of treatment the patient underwent as a result. As a whole, then, Case Studies should be an informative and useful part of every physician's medical education, both during training and on a continuing basis.

It's debatable whether they always achieve this aim. Many journals publish what are often close to anecdotal reports (if they publish articles on individual cases at all), rather than detailed descriptions of a case; furthermore, the cases described are often esoteric or the conditions present on such an infrequent basis that a physician working outside a teachinghospital environment would be hard-pressed to apply their new knowledge. It would be difficult, therefore, to say whether any conclusions could confidently be drawn by readers as a result of these reports. Most physicians would probably want to do some extra
By proposing,

peer-reviewing

and reading

the Case

Studies, you

and your fellow

physicians

could gain

a broader

understanding

of clinical

diagnoses, treatments and outcomes

J Solomon is Assistant Publisher of the

Nature Clinical

Practice series of journals.

\section{Competing interests}

The author declared she has no competing interests.

www.nature.com/clinicalpractice doi:10.1038/ncpendmet0164 research-either in the literature or by canvassing opinions of colleagues.

In this light, then, Nature Clinical Practice Endocrinology \& Metabolism Case Studies have a specific aim: to help established physicians as well as trainees to improve patient care, without adding to their workload. Rather than being merely anecdotal, they include the etiology, diagnosis and management of a case. Importantly, they give an indication of the decision-making process, so that other physicians can apply lateral thinking to their own cases. Decisions on which of a range of treatment options to follow might involve input from the patient, or might be purely objective, but ideally a Case Study should outline why a particular course was followed. Readers should not have to resort to the Internet or to out-of-date textbooks to find basic background information explaining the reasons for approaching the case in that way; the reasons should be fully explained in the article itself.

Nature Clinical Practice Endocrinology \& Metabolism Case Studies represent an opportunity to spread the benefit of knowledge across the physical boundaries imposed by looking at one case, in one place, at one time. It's not so that fingers can be pointed at 'incorrect' treatment but instead so that geographical differences in practice can be highlighted, for example, or clearer descriptions be reached to explain a case more completely and accurately.

By proposing, peer-reviewing and reading the Case Studies, you and your fellow physicians could gain a broader understanding of clinical diagnoses, treatments and outcomes. So, we're inviting you to contribute to the further education of your colleagues. Will you meet the challenge? 